\title{
The Demand for Energy-Using Assets among the World's Rising Middle Classes
}

\author{
By Paul J. Gertler, Orie Shelef, CAtherine D. Wolfram, AND Alan \\ FUCHS*
}

Online Appendix

\begin{abstract}
Appendix A: Model Proofs and Extensions
This appendix provides additional details on the model. First it describes a variety of sufficient and standard assumptions on the third derivative of the utility function for Lemma 2. Second it provides the proof of Lemma 4 and an empirically relevant corollary. Finally, we consider a number of extensions to the model showing that the basic results persist. These include not requiring households who delay purchasing to save, complementarity between income and assets, ongoing energy costs, uncertainty about future income, many assets, and many periods.
\end{abstract}

\section{Assumptions}

In the text, we state the decreasing marginal utility assumption on the utility function. We also assume that the utility function displays decreasing risk 
aversion (absolute or relative), prudence (Kimball, 1990) or a precautionary savings motive (Leland, 1968). ${ }^{1}$ Note that making one of these sorts of assumptions is sensible in a model of savings behavior. Indeed, the alternative assumptions are considered implausible. Further, each of these is a sufficiency condition - weaker conditions do suffice. Less elegant, but sufficient would be that households have a "subsistence" level of food consumption, below which households do not voluntary reduce their consumption and that enough of the households and populations under consideration are near this threshold.

Specifically, for Lemma 2, these weaker assumptions are sufficient.

Set a.-Assume that $u$ is Lipschitz continuous (or that $u^{\prime}$ is uniformly continuous), that $u^{\prime \prime}<\epsilon<0$, and that $a$ is high enough. Lipschitz continuity ensures that the utility function is sufficiently smooth. And thus, the difference between $\partial B / \partial Y_{1}$ and $\partial W / \partial Y_{1}$ is bounded. Since $\frac{\partial W}{\partial Y_{2}}<\delta$ (by epsilon assumption), enough weight on $Y_{2}$ ensures monotonicity in the difference between B and $\mathrm{W}$, and thus single crossing.

Set $b$.-Assume that marginal utility is not decreasing too quickly. To define "too quickly" we need:

$$
\begin{gathered}
\frac{u^{\prime}(\bar{Y})-u^{\prime}(\bar{Y}-P)}{2} \geq 2 u^{\prime}(\bar{Y})-2 u^{\prime}\left(\bar{Y}-\frac{P}{2}\right) \\
\frac{u^{\prime}(\bar{Y})-u^{\prime}\left(\bar{Y}-\frac{P}{2}\right)+u^{\prime}\left(\bar{Y}-\frac{P}{2}\right)-u^{\prime}(\bar{Y}-P)}{2} \geq 2 u^{\prime}(\bar{Y})-2 u^{\prime}\left(\bar{Y}-\frac{P}{2}\right) \\
u^{\prime}\left(\bar{Y}-\frac{P}{2}\right)-u^{\prime}(\bar{Y}-P) \geq 3\left(u^{\prime}(\bar{Y})-u^{\prime}\left(\bar{Y}-\frac{P}{2}\right)\right) \\
u^{\prime}(\bar{Y}-P)-u^{\prime}\left(\bar{Y}-\frac{P}{2}\right) \leq 3\left(u^{\prime}\left(\bar{Y}-\frac{P}{2}\right)-u^{\prime}(\bar{Y})\right)
\end{gathered}
$$

\footnotetext{
${ }^{1}$ Note that all of these apply to the third derivative of the utility function.
} 
which says that $1 / 3$ of decrease in marginal utility from gaining $\frac{P}{2}$ of income at income $\bar{Y}-\frac{P}{2}$ is smaller than the increase in marginal utility from losing $\frac{P}{2}$ of income.

Lemma 4 Proof

$$
\frac{\partial^{2} B}{\partial a \partial \bar{Y}}=-\frac{\partial B}{\partial Y_{1}}+\frac{-(2-a) \bar{Y}}{2}\left(u^{\prime \prime}((2-a) \bar{Y})-u^{\prime \prime}((2-a) \bar{Y}-P)\right)
$$

The first term is positive by decreasing marginal utility. The second term is positive under DARA plus the fact that as $a \rightarrow 2$ the second term goes to zero, while the first does not.

$$
\frac{\partial^{2} W}{\partial a \partial \bar{Y}}=\left[u^{\prime}(a \bar{Y})-u^{\prime}((2-a) \bar{Y})\right]+a \bar{Y} u^{\prime \prime}(a \bar{Y})-(2-a) \bar{Y} u^{\prime \prime}((2-a) \bar{Y})
$$

By decreasing marginal utility the contents of the bracket and the middle term are negative, and the final term is positive. Note that as $a \rightarrow 2$ the final term goes to zero, while the others do not. So, if income is growing fast enough, $\frac{\partial^{2} W}{\partial a \partial \bar{Y}}<0$. Finally, as in Lemma 3, if $a \rightarrow 2$ the saver effect outweighs the buyer effect.

Note: this proof uses $a \rightarrow 2$ both to sign $\frac{\partial^{2} W}{\partial a \partial \bar{Y}}$ and to ensure that there are sufficiently few buyers. For both uses, this is a too strong a sufficient condition. Specifically, to sign $\frac{\partial^{2} W}{\partial a \partial \bar{Y}}$ much weaker assumptions are necessary. E.g. one can sign $\frac{\partial^{2} W}{\partial a \partial \bar{Y}}$ if the prudence motive is not too strong and income is non-decreasing. To see this note that $a \bar{Y} u^{\prime \prime}(a \bar{Y})-(2-a) \bar{Y} u^{\prime \prime}((2-a) \bar{Y}) \leq 0$ if $a \geq 1$ and $u$ displays constant risk aversion. So, by continuity if the prudence motive is sufficiently small (sufficiently small is relative to $a$ ), for all $a$, we also have $\frac{\partial^{2} W}{\partial a \partial \bar{Y}}<0$. 
Corollary to Lemma 4: If the density of $\mathrm{R}$ is sufficiently even or decreasingly dense at least over the relevant region, Lemma 4 holds about the size of each group, not just the range of $\mathrm{R}$.

Proof: If the distribution of $\mathrm{R}$ is uniform, the range of $\mathrm{R}$ is isomorphic to the share of the population. Since the proof of Lemma 4 holds strictly, this holds for a broader class of distributions than uniform. Decreasing density means that the size of the groups are higher at lower valuations. For each income level, lower valuation households are more likely to save than buy, so increasing the range of $\mathrm{R}$ for savers and decreasing the range of $\mathrm{R}$ for buyers also impacts the relevant sizes of the groups.

\section{Extensions}

No savings. - The analysis in the text assumed that the price was sufficiently high that households waiting and buying in period 2 also saved in period 1 . When saving is unnecessary the household is indifferent between not buying and buying in period 2 without savings if, $Y_{2}-Y_{1} \leq P: u\left(Y_{2}\right)-u\left(Y_{2}-P\right)=R$. Call this line B2. Considering B2 adds:

Note that a household buying in period 2 always saves, unless $Y_{2}-Y_{1}>P$

There is the potential of an additional kink at the switch between $\mathrm{W}$ and B2 The earlier results hold with minor modifications when B2 is considered instead of W Thus:

Lemma 1: Note that $\frac{\partial B 2}{\partial Y_{1}}=0$ and $\frac{\partial B 2}{\partial Y_{2}}=u^{\prime}\left(Y_{2}\right)-u^{\prime}\left(Y_{2}-P\right)$

Lemma 2, should be adjusted such that the marginal household at low income buys in period 1, for moderate incomes the marginal household waits to buy, and for high incomes the marginal household buys in period 2 without savings. (One, but not both, of the moderate and high income sets may be empty.) Note that assumption set $b$ has to be adjusted slightly. (In the definition of declining "too quickly" 
instead of $1 / 3$ we need $1 / 2$, and we compare the cost of $\mathrm{P}$ at $\mathrm{Y} 1$ and Y2.)

Lemma 3: Note that $\frac{\partial B 2}{\partial a}=\bar{Y} \frac{\partial B 2}{\partial Y_{2}}$. The proof follows.

Lemma 4: Note that $\frac{\partial^{2} B 2}{\partial a \partial \bar{Y}}=\frac{\partial B 2}{\partial Y_{2}}+a \frac{\partial^{2} B 2}{\partial^{2} Y_{2}}=u^{\prime}\left(Y_{2}\right)-u^{\prime}\left(Y_{2}-P\right)+$ $a\left[u^{\prime \prime}\left(Y_{2}\right)-u^{\prime \prime}\left(Y_{2}-P\right)\right]$, which is negative from the appropriate $3^{\text {rd }}$ derivative assumptions.

So, the earlier results hold considering the composite function of $\mathrm{W}$ and then $\mathrm{B} 2$.

Complementarity between assets.-There are two cases of complementarity between durables and non-durables. Consider a refrigerator as the durable and food as the non-durable. First, there is the general idea that a complementarity exists since food is stored in a refrigerator. Second, the ongoing energy costs of using the refrigerator may enter as a complementarity.

Multiplicative Complementarity adds a few effects. First, complementarity means that the value of the asset increases with income. This is a wealth effect. With even income, this effect is larger for buyers than for savers, because they have the asset for two periods. This effect is smaller with uneven income, especially among buyers. With uneven enough income (e.g. $(2-a) \bar{Y}=P$ ) the effect is larger for savers than buyers (since the buyers consume 0 food in the first period, they only experience 1 period of complementarities).

Second, complementarity means that savers may choose to delay consumption to gain the complementarity with the asset in the second period by saving more. Particularly, savers will no longer consume evenly. This delay reduces the costs of buying instead of saving, so more households will buy. In general, it is difficult to sign how this effect interacts with income because the effect itself depends on the ratio of the curvature to slope ( $\left.u^{\prime \prime} / \mathrm{u}^{\prime}\right)$ and the change of that with income depends on the ratio of u"'/u", both with respect to the complementarity. However, The delay is decreasing in $a$, and for a large enough $a$ or $Y$, no delay is 
made (these are B2 buyers, note that B2 buyers at moderate $a$ may now save in period 1 to gain the complementarity.)

Together this suggests that complementarity is an independent reason for acquisition to increase with income. And, depending on the shape of the complementarity with income, complementarity may be an independent source of the S-shape of prediction 1, or a countervailing force. If income is sufficiently uneven, none of the earlier results change meaningfully - the income effect is larger for savers, so most of the results are strengthened.

Moreover, complementarity does not meaningfully change the no credit constraint model, so the comparative statics are still useful to distinguish the two. Formally, model the multiplicative complementarity as the refrigerator having the same static utility $R$, as well as a complementarity with food such that consuming $f$ units of food yield per period utility $r u(f)$ with $r>1$ implying complementarity. We will assume that the complementarity is not so strong so that the wealth effect exceeds the cost of the refrigerator: $r u\left(\bar{Y}-\frac{P}{2}\right) \ll u(\bar{Y})$.

Absent credit constraints, the household buys if and only if

$$
u(\bar{Y})-r u\left(\bar{Y}-\frac{P}{2}\right) \leq R
$$

$r u\left(\bar{Y}-\frac{P}{2}\right)$ is increasing with income faster than $u(\bar{Y})$ both because of complementarity and decreasing marginal utility.

Case 1: indifferent between buying in period 1 and not buying if $\frac{u\left(Y_{1}\right)-r u\left(\left(Y_{1}-P\right)\right)}{2}+\frac{u\left(Y_{2}\right)-r u\left(\left(Y_{2}\right)\right)}{2}=R$. Call this $B^{c}$

Case 2: buy in period 2: $u\left(Y_{1}\right)+u\left(Y_{2}\right)-u\left(\bar{Y}-\frac{P}{2}-y_{r}\right)-r u\left(\bar{Y}-\frac{P}{2}+\right.$ $\left.y_{r}\right)=R$. Call this $W^{c}$

Where $y_{r}$ is extra savings the household chooses to make to equate marginal utilities. That is such that $u^{\prime}\left(\bar{Y}-\frac{P}{2}-y_{r}\right)=r u^{\prime}\left(\bar{Y}-\frac{P}{2}+y_{r}\right)$

\section{Lemma 1c:}

$$
\frac{\partial B^{c}}{\partial y_{1}}=\frac{u^{\prime}\left(Y_{1}\right)-r u^{\prime}\left(Y_{1}-P\right)}{2}
$$




$$
\begin{gathered}
\frac{\partial B^{c}}{\partial y_{2}}=\frac{u^{\prime}\left(Y_{2}\right)-r u^{\prime}\left(Y_{2}\right)}{2} \\
\frac{\partial W^{c}}{\partial Y_{1}}=u^{\prime}\left(Y_{1}\right)-u^{\prime}\left(\bar{Y}-\frac{P}{2}-y_{r}\right) \\
\frac{\partial W^{c}}{\partial Y_{2}}=u^{\prime}\left(Y_{2}\right)-u^{\prime}\left(\bar{Y}-\frac{P}{2}-y_{r}\right)
\end{gathered}
$$

Lemma 2c: Follows similar logic as Lemma 2.

A sufficient condition for $\frac{\partial W^{c}}{\partial Y_{2}}<\frac{\partial B^{c}}{\partial Y_{2}}$ is that $\bar{Y}-\frac{P}{2}+y_{r} \leq Y_{2}$ which must hold near their intersection, since otherwise the household strictly prefers to purchase in period 1 .

Note that $\frac{\partial W^{c}}{\partial Y_{1}}<\frac{\partial W}{\partial Y_{1}}$ and $\frac{\partial B^{c}}{\partial Y_{1}}=\frac{\partial B}{\partial Y_{1}}-\frac{r-1}{2} u^{\prime}\left(Y_{1}-P\right)$ and the second term is finite in the relevant region $Y_{1}-P \gg 0$.

Lemma 3c: The proof follows similarly for $\frac{\partial W^{c}}{\partial a}$ since $u^{\prime}\left(\bar{Y}-\frac{P}{2}-y_{r}\right)$ doesn't depend on a.

For $\frac{\partial B^{c}}{\partial a}=-\bar{Y} \frac{\partial B^{c}}{\partial Y_{1}}+\bar{Y} \frac{\partial B^{c}}{\partial Y_{2}}$. With expansion and algebra it has the same sign as: $\quad \frac{r}{2}\left(\left(u^{\prime}\left(Y_{1}-P\right)-u^{\prime}\left(Y_{1}\right)\right)-\left(u^{\prime}\left(Y_{2}-P\right)-u^{\prime}\left(Y_{2}\right)\right)\right)+\frac{r}{2} u^{\prime}\left(Y_{2}-P\right)+$ $\frac{1}{2} u^{\prime}\left(Y_{2}\right)$. The second and third terms are strictly positive. The $1^{\text {st }}$ term is positive under DARA (and bounded below by appropriate adjustments to the alternative assumptions)

Lemma 4: The proof is similar for $W^{c}$ again because $u^{\prime}\left(\bar{Y}-\frac{P}{2}-y_{r}\right)$ doesn't depend on a.

$\frac{\partial^{2} B^{c}}{\partial a \partial \bar{Y}}=\frac{\frac{\partial B^{c}}{\partial a}}{\bar{Y}}-\bar{Y}(2-a) \frac{\partial^{2} B^{c}}{\partial^{2} Y_{1}}+a \bar{Y} \frac{\partial^{2} B^{c}}{\partial^{2} Y_{2}}$. Note that by the above proof, the first term is positive. By DARA the last term is positive, and as $a \rightarrow 2$ the middle term goes to zero.

In the case of per period electricity costs $e$ we can relabel the savers as the asset as having $\operatorname{cost} P^{\prime}=P+e$, and they behave as before. Buyers have the same new price $p^{\prime}$, but face a second cost in utility terms of $u\left(Y_{2}\right)-u\left(Y_{2}-e\right)$. Note that 
this cost makes the refrigerator effectively complementary with income. But, as long as $P>e$, (so that $\frac{P^{\prime}}{2}>e$, and households who save spend more out of consumption for the refrigerator in the $2^{\text {nd }}$ period than buyers spend in the second period) the rest of the results hold.

Uncertainty.-Uncertainty is a relevant concern in that a household making a decision in period 1 may not have precise information about period 2 income. Particularly, second period income may have some expected distribution $Y_{2} \sim G(\cdot)$. Precautionary savings is particularly relevant because in this type of setting, a household may choose to save for precautionary reasons. That is, because the household should not equate income, but equate marginal utility, even if $Y_{1}=$ $E\left(Y_{2}\right)$ the household would prefer to delay some amount of income $d$ so that $Y_{1}-$ $d<E\left(Y_{2}\right)-d$ and $u^{\prime}\left(Y_{1}-d\right)=E\left(u^{\prime}\left(Y_{2}+d\right)\right)$. So even without the availability of, or plan to purchase, an asset, the household delays income.

Uncertainty has three main impacts on the predictions of the conceptual framework. First, precautionary savings provides a source of credit for the household, self-financing. A household who planned to save $d$ absent acquiring the asset, is like a household with income $Y_{1}-d$ and $Y_{2}+d$ with the ability to borrow freely an amount up to $d$ from the second period. Second, precautionary savings is complementary with delaying purchase, saving for the asset, and purchasing in the second period. Even with no change in savings behavior, the availability of the asset in the second period provides an option value to the savings. The value of the precautionary savings is increased because it can be used to purchase the asset if the household realizes high second period income, and consumed if the household realizes low second period income. Likewise, savings that in the certain case were planned to be used for asset acquisition can be consumed following a bad income realization. Third, households that delay, and do not purchase in the first period, may, upon realization of a bad outcome in the second period, not buy. 
It is straightforward to argue that with sufficient income growth, the predictions of the model are unchanged. However, to demonstrate that this limit type argument is not necessary, we consider the predictions in the context of a specific form of uncertainty $G(\cdot) \sim N\left(Y_{2}, \sigma^{2}\right)$ and a functional form for the utility of food $u(c)=-\frac{1}{\beta}\left(e^{-\beta c}-1\right)$.

From these assumptions the utility of the household with consumption path $Y_{1}, Y_{2}$ has expected utility $u\left(Y_{1}\right)+u\left(Y_{2}-\frac{\beta \sigma^{2}}{2}\right)$. Absent the purchase decision, this household would choose to save a weakly positive amount $d$ in period 1 so that $Y_{1}-d=Y_{2}+d-\frac{\beta \sigma^{2}}{2}$. The functional form gives a tractable functional form where precautionary savings depends only on the unevenness of income and the nature of uncertainty, and not income level itself.

Note that acquisition will add to this not only the changes in consumption and the direct utility of the asset, but the option value of buying the asset following good realizations. From that and given the unbounded uncertainty, households always prefer to delay purchasing (potentially without saving) compared to committing to never purchase - because for some realization of second period income, buying the asset is ex-post optimal.

We focus primarily on the case when uncertainty is moderate relative to the price. That is $P>\frac{\beta \sigma^{2}}{4}$, and comment on further adjustments if uncertainty is high. The main distinction follows because with enough income and high uncertainty, even households who purchase in the first period may choose to save additional income for precautionary reasons.

Lemma 1: Under moderate uncertainty, a household buying immediately does not save; and saving households save at most the larger of 0 and $\frac{\beta \sigma^{2}}{4}+$ $\frac{P}{2}-\left(Y_{2}-Y_{1}\right)$. If uncertainty is moderate and delaying household save some positive amount, Lemma 1 follows directly, except for $\partial B / \partial Y_{2}$. If uncertainty is moderate, and income is sufficiently even, then the non-acquiring household saves less with increases in $Y_{2}$ and thus has greater welfare 
increases than buyers. In that case $\frac{\partial B}{\partial Y_{2}}>0$. For sufficiently high uncertainty, or uneven income, such that both non-acquirers and immediate buyers save, or neither do, $\frac{\partial B}{\partial Y_{2}}<0$. For the case of non-acquirers not saving, see the extensions to consider B2.

Lemma 2: Under moderate uncertainty, we need only that $\frac{\partial W}{\partial Y_{1}}-\frac{\partial B}{\partial Y_{1}}$ is bounded from above. This follows from the same intuition as in the text. If the household is saving the increases in $Y_{1}$ are split through the savings between periods, while the buying household experiences all the increase in $Y_{1}$ in period 1. Moreover, for any income level, if the non-acquiring household would save, the marginal household must save and purchase with positive probability. This follows because reducing $R$ reduces the welfare of the delaying household by less than $R$, but the welfare of the buying household by 2R. A caveat on the corollary to Lemma 2: with uncertainty, planning to delay and saving is not the same as planning to purchase. However, if the uncertainty is small, the correlation is high.

Lemma 3: It follows directly that changes in $a$ leave unchanged the welfare from any choice with savings. If the non-acquiring household saves, then delayers who save have welfare unchanged, households who buy immediately reduce their welfare, and households who delay without saving reduce their welfare. Moreover, because households who delay without saving have more even consumption than households who buy immediately, their welfare is reduced less. Lemma 3 follows.

Lemma 4: This follows by a similar argument. First note that among savers, there is no change in utility with $a$. For non-saving immediate buyers, welfare may be increased more than non-acquirers at sufficiently low level of income of sufficiently even income, increasing buyers. However, at higher levels of income and/or $a$ this no longer holds. Similarly, when income levels and unevenness are such that non-acquirers do not save and delayers do, delayers gain more than non-acquirers from income changes, and non- 
acquirers lose from increases in $a$. In regions where no household saves, see earlier extensions.

Price Changes.-There is a long literature about the dynamic pricing decisions of a durable good monopolist that is particularly relevant to pricing of new innovative goods. While the goods in our setting are not particularly innovative, we are studying the adoption of these goods by new populations and, in principle, a seller with market power may have time-varying prices. Durable goods may also be subject to price trends driven by changing cost structures. Our focus here is not on the optimal pricing decisions of the seller or the source of the price trends, but how consumers respond to these prices.

Anticipated price changes: The focus of the dynamic pricing literature is that sellers have predictable incentives to price dynamically which consumers recognize. That is, prices in the second period will be different in anticipated ways. Anticipated price changes can change the acquisition patterns of households without credit constraints - as in the classic durable good monopolist problems. Expected decreases sufficiently large compared to the household's R will cause marginal households to delay. Anticipated price increases have no effect on households with access to credit, because they never find it optimal, even with constant prices, to buy in the second period. However, the results of the model follow directly with anticipated price changes. Replacing P in the model with period specific prices $P_{1}$ and $P_{2}$, we note that $B$ is a function of only $P_{1}$ and $W$ is a function of only $P_{2}$. Lemma 1 does not compare $B$ and $W$, and note that the relevant derivatives of $W$ in Lemma 3 and Lemma 4 drop $P_{2}$. What remains is for Lemma 2 to show that $\frac{\partial W}{\partial Y_{1}}-\frac{\partial B}{\partial Y_{1}}=\frac{u^{\prime}\left(Y_{1}\right)-u^{\prime}\left(Y_{1}-P_{1}\right)}{2}-\left(u^{\prime}\left(Y_{1}\right)-u^{\prime}\left(\bar{Y}-\frac{P_{2}}{2}\right)\right)$ is bounded from above. This follows from conditions analogous to those discussed earlier in the appendix.

Uncertain Prices: Uncertainty about prices functions much in the same way as uncertainty about income. Income uncertainty has two effects on the household in the second period - income shocks, and changes in the relative prices of the durable relative to the marginal unit of the non-durable good. Price shocks are 
direct shocks to relative prices. They are, however, also real income shocks if the household purchases the good in period 2. Note that all households who did not purchase in period 1 purchase in period 2 for some realization of prices. Thus, price uncertainty functions in ways similar to (real) income uncertainty.

Many assets.-The robustness concern with multiple assets would be that households may acquire individual assets in a nonlinear fashion, but that aggregating across assets results in a smooth function. To fix ideas, suppose there were two assets. Asset $\mathrm{A}$, with a low price $P_{A}$, low per period value $R_{A}$, and Asset B with higher price $P_{B}$ and higher per period value $R_{B}$. Assets are neither complements nor substitutes.

With many assets, the time path of income is still important, in the same manner as it was in the main model. To see this, suppose the unconstrained household with income $\bar{Y}$ chooses not to buy asset A. It must also be the case that a household with the same income evenly split between periods would not save and acquire it (the household receives 1 period of benefit, for the same utility cost as the unconstrained household.). Likewise, the credit constrained household would not buy it immediately (same benefit, higher cost). However, with sufficiently uneven income, the household may delay purchasing it, and may even engage in complementary savings to acquire it. The presence of the second asset does not change these underlying factors.

For a particular income range, under even income, there is a particular ordering of assets:

For example. Consider the choice of a household between buying A in period 1 and $B$ in period 2 and the reverse. Swapping orders gains utility $R_{B}-R_{A}$ at the cost of adding inequality of consumption between periods by consuming $\frac{P_{B}-P_{A}}{2}$ more in the second period and $\frac{P_{B}-P_{A}}{2}$ less in the second period. As income unevenness between the periods rises, that cost grows. As income levels grow that cost decreases. 
Acquisition of assets is still nonlinear

Because assets are not equivalent quanta even a household planning to buy one asset each period acquires assets nonlinearly.

Even if assets were equivalent quanta, the incentives to delay acquisition and acquire nonlinearly exist because of income growth. E.g. increasing income unevenness increases the cost of a purchase in period 1 and decreases the cost of that purchase in period 2, leading to delay.

Cash savings, forced and complementary, still happen.

Consider the household planning to buy A in period 1 and B in period 2 with even income. That household saves between periods.

Consider the household planning to buy A in period 2 and B in period 1 with even income. As income becomes more uneven period 2 purchases become cheaper and period 1 purchases become more expensive in utility terms. This can lead the household to swap asset orders, which amounts to forced savings. Further, if the forced savings are not quite large enough, the household will undertake complementary savings.

Income unevenness can reduce purchases of A.

Consider the household planning to buy A in period 1 and B in period 2 with even income. Initial income unevenness only displaces planned savings. Once savings is exhausted, income unevenness increases the cost of period 1 purchases and decreases the cost of period 2 purchases. This household either delays or stops purchasing of A as income unevenness increases. Purchases of B are maintained because even if the household choose to purchase A in period 2 as well, the household will save to do so, so that the marginal cost of B is weakly decreasing in unevenness.

Despite the various purchase plans available to the households, analysis of each shows that in each case there is a single asset, different asset, or 
composite asset on which the household may be marginal on facing either an increase in income or an increase in growth.

For households that do not purchase in the first period (i.e., ultimately consume $(0,0),(0, A),(0, B)$, or $(0, A B)$, where the first argument is the first period acquisition and the second argument is the second period acquisition.) or purchase both in the first period $(A B, 0)$, it is generically the case that only one asset is marginal, so the same comparative statics apply.

Households that purchase only one asset in the first period $(\mathrm{A}, 0)$ or $(B, 0)$ may either delay their current planned purchase, add the other asset in either period, switch assets, or switch assets and delay. Delaying the current asset or adding the other asset is well defined in the one asset context. Switching to the other asset, or switching to the other asset and delaying purchase can be seen as a decision to delay or add another asset where the new asset is a composite of assets A and B. Thus, the same comparative statics apply.

Households that plan to acquire one asset in each period could, potentially, reorder assets. Consider the household with plan (B,A). Income growth may shift this household to (A,B), among other choices, reordering assets. However, this is still well defined as delay, as the household delays B-A worth of assets to the second period. The household with plan A,B, if it were to switch to B,A, would not be well defined as a delay or reduction in assets. Note that this switch would effectively be an acceleration of an asset B-A. The previous standard analysis on this difference applies, and it would only be accelerated under the same conditions that increase first period purchasing.

As such, for each household, the aggregate comparative statics for the one asset case, extend locally to the two asset case.

Lemma 2 uses the presence of a single kink. With multiple assets there may be many kinks, but each kink shares the feature that saving is more steep than 
buying. Moreover, when the "buying" choice from one kink is the same decision as the "saving" choice from another kink, they must have the same slopes. Added together, the curve then is an S-shape with many kinks.

Lemmas 3 and 4 aggregate through an assumption that there are "enough" savers. Similarly, with many assets for Lemmas $3 \& 4$ to aggregate, enough savers are required. $a \rightarrow 2$ is sufficient with many assets, though the impact may not be monotonic for levels of $a \ll 2$. More over smaller levels of $a$ as well as particular patterns of valuations and prices would also be sufficient.

Additional periods. - The model can readily be extended to allow more than two periods. Consider 3.

The utility of each choice is:

The household who never buys has utility $u\left(Y_{1}\right)+u\left(Y_{2}\right)+u\left(Y_{3}\right)$

The household who buys in period 1 has utility $u\left(Y_{1}-P\right)+u\left(Y_{2}\right)+$ $u\left(Y_{3}\right)+3 R$

The household who buys in period 2 and saves to purchase has utility $2 u\left(\frac{Y_{1}+Y_{2}-P}{2}\right)+u\left(Y_{3}\right)+2 R$

The household who buys in period 2 without saving has utility $u\left(Y_{1}-P\right)+u\left(Y_{2}-P\right)+u\left(Y_{3}\right)+2 R$

The household who buys in period 3 and saves over all periods to purchase has utility $3 u\left(\frac{Y_{1}+Y_{2}+Y_{3}-p}{3}\right)+R$

The household who buys in period 3 and saves over two periods to purchase has utility $2 u\left(\frac{Y_{2}+Y_{3}-p}{2}\right)+u\left(Y_{1}\right)+R$

The household who buys in period 3 without saving has utility $u\left(Y_{1}\right)+u\left(Y_{2}\right)+u\left(Y_{3}-P\right)+R$

Note that creating indifference surfaces from each purchase with respect to the never buying produces, with slight adjustment to the denominator reflecting an extra period, B, W, B2, and three new surfaces that reflect purchase in the final period. Recreating the Lemmas follows directly. 
We note one more consequence of income growth from this three period model. Consider what happens to behavior when $Y_{3}$ increases. Households that were marginal in the decision to never purchase, purchase in the first period, or purchase in the second period are now more likely to purchase in third period. This effectively steepens the S-curve observed in period 2 by raising the kink there are fewer purchases in periods 1 and 2. Because lower income and lower valuations of the asset increase the probability of being marginal, those reduced purchases disproportionally come from those households with lower incomes. This thus steepens the S-curve. 


\section{APPENDIX B: Additional Summary Statistics}

APPENDIX TABLE 1 -SUMMARY STATISTICS

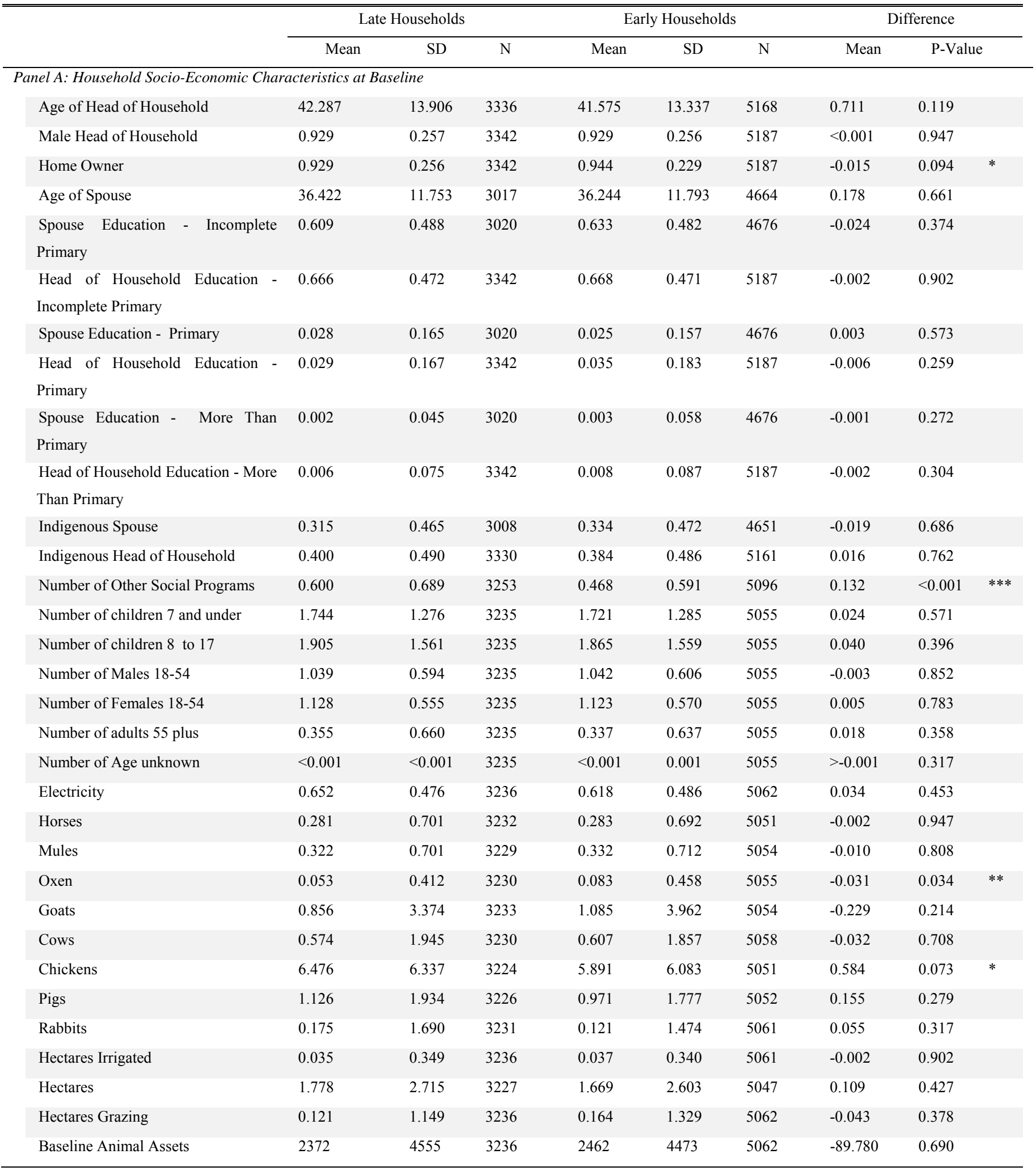


APPENDIX TABLE 1 -SUMMARY STATISTICS (CONTINUED)

\begin{tabular}{|c|c|c|c|c|c|c|c|c|}
\hline & \multicolumn{3}{|c|}{ Late Households } & \multicolumn{3}{|c|}{ Early Households } & \multicolumn{2}{|c|}{ Difference } \\
\hline & Mean & SD & $\mathrm{N}$ & Mean & SD & $\mathrm{N}$ & Mean & P-Value \\
\hline \multicolumn{9}{|l|}{ Panel B: Village Characteristics } \\
\hline Migration Intensity & 0.056 & 1.024 & 168 & 0.039 & 0.991 & 272 & 0.017 & 0.864 \\
\hline $\begin{array}{l}\text { Degree of Marginalization Low or } \\
\text { Moderate }\end{array}$ & 0.077 & 0.267 & 168 & 0.091 & 0.288 & 274 & -0.014 & 0.608 \\
\hline Degree of Marginalization High & 0.756 & 0.430 & 168 & 0.719 & 0.450 & 274 & 0.037 & 0.389 \\
\hline $\begin{array}{l}\text { Degree of Marginalization Very } \\
\text { High }\end{array}$ & 0.167 & 0.373 & 168 & 0.190 & 0.393 & 274 & -0.023 & 0.536 \\
\hline KM to Nearest City & 101.033 & 43.548 & 171 & 102.285 & 41.002 & 275 & -1.252 & 0.763 \\
\hline
\end{tabular}


APPENDIX TABLE 2-SUMMARY STATISTICS: DEPENDENT VARIABLES

\begin{tabular}{|c|c|c|c|c|c|c|c|c|}
\hline & \multicolumn{3}{|c|}{ Late Households } & \multicolumn{3}{|c|}{ Early Households } & \multicolumn{2}{|c|}{ Difference } \\
\hline & Mean & SD & $\mathrm{N}$ & Mean & SD & $\mathrm{N}$ & Mean & P-Value \\
\hline \multicolumn{9}{|c|}{ Assets - Dependent Variables At Baseline } \\
\hline Refrigerator & 0.038 & 0.191 & 3341 & 0.044 & 0.205 & 5185 & -0.006 & 0.540 \\
\hline Washing & 0.012 & 0.109 & 3342 & 0.014 & 0.119 & 5184 & -0.002 & 0.600 \\
\hline \multicolumn{9}{|l|}{ Machine } \\
\hline Stove & 0.165 & 0.371 & 3342 & 0.158 & 0.364 & 5186 & 0.007 & 0.777 \\
\hline TV & 0.352 & 0.478 & 3341 & 0.312 & 0.463 & 5185 & 0.040 & 0.165 \\
\hline Blender & 0.201 & 0.401 & 3342 & 0.166 & 0.372 & 5185 & 0.035 & 0.113 \\
\hline Radio/Stereo & 0.586 & 0.493 & 3342 & 0.562 & 0.496 & 5186 & 0.024 & 0.291 \\
\hline Fan & 0.040 & 0.195 & 3341 & 0.028 & 0.166 & 5184 & 0.011 & 0.248 \\
\hline Car & 0.004 & 0.060 & 3341 & 0.006 & 0.077 & 5184 & -0.002 & 0.365 \\
\hline Water Heater & 0.018 & 0.133 & 3335 & 0.018 & 0.133 & 5172 & 0.000 & 0.998 \\
\hline
\end{tabular}

Source: Encuesta de Características Socioeconómicas de los Hogares (1997) 


\section{Appendix C: Income Effects}

This appendix focuses on the use of household income, rather than household transfers, as the variable of interest. This appendix shows that the results are robust to this alternative specification, consistent with the assumption that the net impact of transfers on total household income is close to total transfers. That is, the net substitution and income effects are small.

For each survey round, we calculate household income by summing reported primary labor income, unearned income, public transfer income (excluding reported Oportunidades income), and private transfers. Primary wage income is calculated by multiplying labor supply of each individual in the household times a variable measuring the median wage by state, occupation and age bin. Each income source is annualized according to the report period for which it applies. For each category of income, the top $2 \%$ are winsorized. To these, actual Oportunidades transfers are added. Annual income is inflation adjusted to 2003 pesos and accumulated across rounds, with linear imputation for years in which surveys were not available and to account for seasonality issues for March surveys, and added to baseline animal assets to capture income accumulated before surveying began. We also estimate specifications using "cumulative wages", which we define to include only labor income and Oportunidades transfers.

In Appendix Tables 3-5, we report results using income measures for similar specifications to those used in the main text. In general, the results are overwhelmingly similar to those reported in the main text. The results in Appendix Table 4 that do not include household fixed effects suggest a smaller differential between households with high baseline assets and those with low, although the differences are still statistically significant. We suspect the differential response of households with more assets at baseline is smaller in the income specifications because, controlling for income, baseline assets are less informative about a household's wealth.

We also compare the relationship between cumulative income, wages, and transfers with potential cumulative transfers. We regress each measure of 
cumulative income on potential cumulative transfers, using the same sets of controls as described in the notes to Table 4. This is actually equivalent to the first stage of Table 4 .

The coefficient on PCT in the cumulative transfers specification is $0.455^{* * *}$ [0.009]. This reflects that for each peso of potential cumulative transfers, households received about 45.5 cents. Several factors may explain why this number is smaller than 1. For example, it is unlikely that the program caused children who had already left school to return though these children are included in the potential transfers calculation. Also, approximately 10 percent of the households did not enroll in the program.

The coefficient on PCT from the cumulative wages specification is $0.428 * * *$ [0.052]. This coefficient is not statistically different than the transfers specification and very similar economically. Taken at the point estimates, these imply that for every peso of potential cumulative transfers, households reduced wage income by 2.7 cents, though we cannot reject the null of no wage income substitution. Because the window of the data is only 5 years, the investment effect through education is unlikely to appear yet in labor income. As such this coefficient is consistent with the small labor substitution effects documented elsewhere.

The respective coefficient on PCT from the cumulative income specification is $0.568 * * *$ [0.060]. This coefficient is statistically distinguishable from the cumulative transfers specification, but reflects a modest investment effect. The point estimate implies that the household receives an additional 14.0 cents in investment income. With the measurement bias discussed in the text, these 14.0 cents include both the investment returns and the return of the invested capital. ${ }^{2}$ We report, in Appendix Table 6, the first stages from the main specifications.

\footnotetext{
2 The investment income estimate is consistent with the investment returns estimated in Gertler et al. (2012). They find households invest approximately $26 \%$ of transfers, or about 12 cents per pesos of potential transfers. 12 months after investing, households receive monthly income, potentially earnings and return of principal, equal to about $6 \%$ of the investment amount (about 0.7 cents/month). By 2003 households would have received an average of 20 months of this monthly income, which yields roughly 14 cents in investment income per peso of potential transfers.
} 
Additionally, we report two tests - one for the early households and one for the late households - that restrict the first stage to the first year in which households receive transfers. If there are lags in the return to investment, the coefficient for the first year should not reflect investment returns yet. For late households in 2000, after about a year of transfers, the coefficient on PCT is $0.354 * * *$ [0.013] and $0.361^{*}$ [0.215] for transfers and income respectively. Similarly, for early households in 1998, after about half a year of transfers, the coefficients are $0.117 * * *[0.006]$ and $0.197 *[0.116]$. The coefficients from transfers and income are not statistically distinguishable, and we cannot reject the null of no investment effect.

Finally, we examine whether there are any nonlinearities in the relationship between PCT and Cumulative Income. Appendix Figure 1 shows that the relationship is strongly linear. Our primary concern would be that if wealthier households have more investment opportunities, or are able to divert more of their transfers to profitable investment opportunities, the nonlinear responses of acquisition to transfers might be a function of these underlying nonlinearities. 
APPENDIX TABLE 3-BASIC RESULTS:

REFRIGERATOR - WEALTH EFFECTS - INCOME

\begin{tabular}{|c|c|c|c|}
\hline & (1) & (2) & (3) \\
\hline & OLS & IV & IV \\
\hline & \multicolumn{2}{|c|}{ Discrete Time Hazard } & Household FE \\
\hline Cumulative Income $\mathrm{X}$ Bottom & $0.003 * * *$ & $0.015 * * *$ & $0.033 * * *$ \\
\hline $75 \%$ of Baseline Assets & {$[0.001]$} & {$[0.006]$} & {$[0.007]$} \\
\hline Cumulative Income X Top $25 \%$ & $0.004 * * *$ & $0.018 * * *$ & $0.035 * * *$ \\
\hline of Baseline Assets & {$[0.001]$} & {$[0.005]$} & {$[0.007]$} \\
\hline \multirow[t]{2}{*}{ Difference } & $0.002 *$ & $0.003 * *$ & 0.002 \\
\hline & {$[0.001]$} & {$[0.001]$} & {$[0.001]$} \\
\hline $\mathrm{N}$ & 30,414 & 30,414 & 30,258 \\
\hline R-squared & 0.104 & & \\
\hline $\begin{array}{l}\text { Kleibergen-Paap Wald F Stat on } \\
\text { Excluded Variables }\end{array}$ & & 46 & 52 \\
\hline Number of Households & & & 6,655 \\
\hline
\end{tabular}

APPENDIX TABLE 4-BASIC RESULTS:

REFRIGERATOR - INCOME AND WEALTH EFFECTS - WAGES

\begin{tabular}{|c|c|c|c|c|c|c|}
\hline & (1) & (2) & (3) & (4) & (5) & (6) \\
\hline & OLS & IV & IV & OLS & IV & IV \\
\hline & \multicolumn{2}{|c|}{ Discrete Time Hazard } & Household FE & \multicolumn{2}{|c|}{ Discrete Time Hazard } & Household FE \\
\hline Cumulative Wages X Bottom & & & & $0.002 *$ & $0.019 * * *$ & $0.037 * * *$ \\
\hline $25 \%$ of Baseline Assets & & & & {$[0.001]$} & {$[0.008]$} & {$[0.008]$} \\
\hline \multirow[t]{2}{*}{ Difference } & & & & 0.002 & $0.005 * * *$ & $0.005 * *$ \\
\hline & & & & {$[0.001]$} & {$[0.002]$} & {$[0.002]$} \\
\hline Number of Households & & & 6,655 & & & 6,655 \\
\hline
\end{tabular}


APPENDIX TABLE 5-BASIC RESUltS:

REFRIGERATOR - TIMING EFFECT - WAGES

\begin{tabular}{|c|c|c|c|c|c|}
\hline & $\begin{array}{l}(1) \\
\text { OLS }\end{array}$ & $\begin{array}{l}(2) \\
\text { OLS }\end{array}$ & $\begin{array}{l}\text { (3) } \\
\text { OLS }\end{array}$ & $\begin{array}{l}(4) \\
\text { IV }\end{array}$ & $\begin{array}{l}\text { (5) } \\
\text { IV }\end{array}$ \\
\hline & \multicolumn{4}{|c|}{ Discrete Time Hazard } & Household FE \\
\hline Cumulative Wages & $\begin{array}{l}0.002 * * * \\
{[0.001]}\end{array}$ & $\begin{array}{l}0.002 * * \\
{[0.001]}\end{array}$ & $\begin{array}{l}0.003 * * * \\
{[0.001]}\end{array}$ & $\begin{array}{l}0.037 * * * \\
{[0.008]}\end{array}$ & $\begin{array}{l}0.045^{* * *} \\
{[0.009]}\end{array}$ \\
\hline Early & & $\begin{array}{l}-0.004 \\
{[0.005]}\end{array}$ & $\begin{array}{l}-0.001 \\
{[0.005]}\end{array}$ & $\begin{array}{l}0.008 \\
{[0.007]}\end{array}$ & \\
\hline Cumulative Wages X Early & & & $\begin{array}{l}-0.001 \\
{[0.001]}\end{array}$ & $\begin{array}{l}-0.004^{* *} \\
{[0.002]}\end{array}$ & $\begin{array}{l}-0.003 \\
{[0.002]}\end{array}$ \\
\hline $\begin{array}{l}\text { Compensating Transfer at } 2003 \text { Median } \\
\text { Cumulative Wages (Ten Thousand P }\end{array}$ & esos) & & $\begin{array}{l}3.800 \\
{[5.959]}\end{array}$ & $\begin{array}{l}1.088^{* *} \\
{[0.530]}\end{array}$ & \\
\hline $\begin{array}{l}\mathrm{N} \\
\mathrm{R} \text {-squared }\end{array}$ & $\begin{array}{l}30,414 \\
0.102\end{array}$ & $\begin{array}{l}30,414 \\
0.103\end{array}$ & $\begin{array}{l}30,414 \\
0.103\end{array}$ & 30,414 & 30,258 \\
\hline $\begin{array}{l}\text { Kleibergen-Paap Wald F Stat on Exclud } \\
\text { Number of Households }\end{array}$ & led Variables & & & 36 & $\begin{array}{l}47 \\
6,655\end{array}$ \\
\hline
\end{tabular}

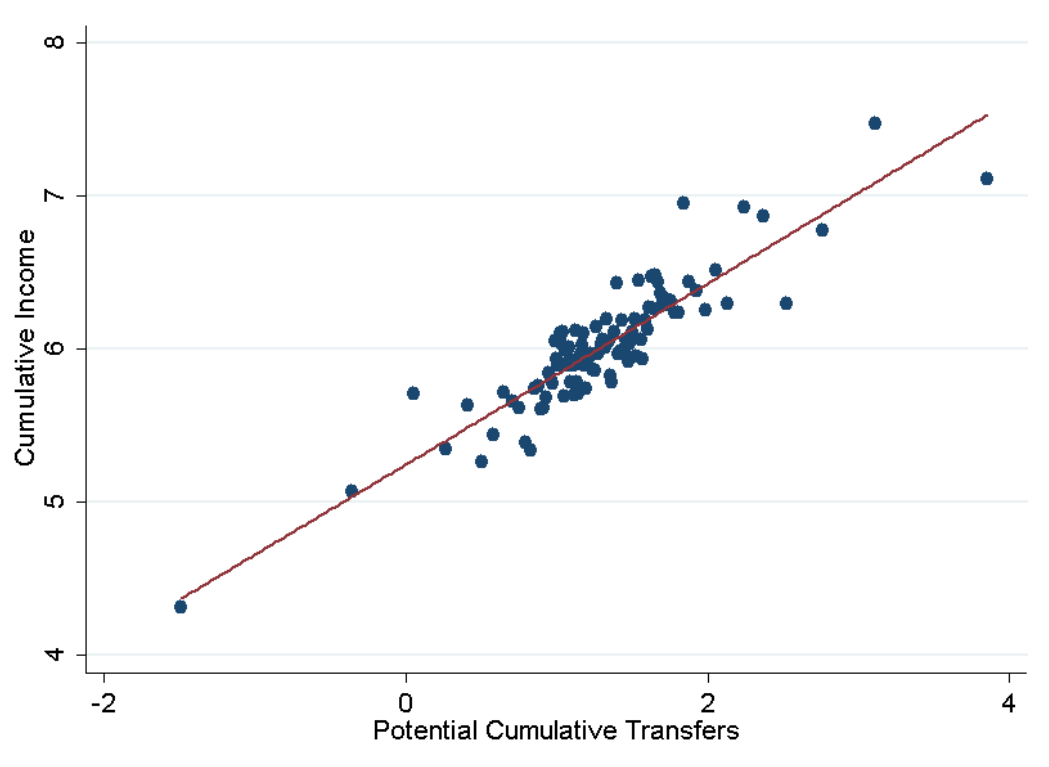

APPENDIX FIGURE 1: LINEAR RELATIONSHIP BETWEEN POTENTIAL CUMULATIVE TRANSFERS AND CUMULATIVE INCOME

Notes: Each point is the average cumulative income and average PCT (both in 10 thousand pesos) in bins of PCT after controlling for the same controls as in Table 4 . The fitted line is a fitted quadratic. 
APPENDiX TABLE 6-First StAGES

\begin{tabular}{|c|c|c|c|c|c|}
\hline & PCT & $\begin{array}{l}\text { PCT X } \\
\text { Early }\end{array}$ & $\begin{array}{l}\text { PCT X Baseline } \\
\text { Animal Assets }\end{array}$ & $\begin{array}{c}\text { PCT X } \\
\text { Low Assets }\end{array}$ & $\begin{array}{l}\text { PCT X High } \\
\text { Assets }\end{array}$ \\
\hline Table 4, Column 2: Cumulative Transfers & $\begin{array}{l}0.4554^{* * *} \\
{[0.0091]}\end{array}$ & & & & \\
\hline Table 4, Column 3: Cumulative Transfers & $\begin{array}{l}0.4997 * * * \\
{[0.0110]}\end{array}$ & & & & \\
\hline Table 4, Column 5: Cumulative Income & $\begin{array}{l}0.5700^{* * *} \\
{[0.0595]}\end{array}$ & & & & \\
\hline Table 4, Column 6: Cumulative Income & $\begin{array}{l}0.6801 * * * \\
{[0.0655]}\end{array}$ & & & & \\
\hline Table 5, Column 2: Cumulative Income & $\begin{array}{l}0.5616^{* * *} \\
{[0.0625]}\end{array}$ & & $\begin{array}{l}<0.0001 \\
{[<0.0001]}\end{array}$ & & \\
\hline Table 5, Column 2: Cumulative Income2 & $\begin{array}{l}10.1613^{* * *} \\
{[2.4072]}\end{array}$ & & $\begin{array}{l}0.0013^{* * *} \\
{[0.0003]}\end{array}$ & & \\
\hline Table 5, Column 3: Cumulative Income & $\begin{array}{l}0.6636^{* * * *} \\
{[0.0666]}\end{array}$ & & $\begin{array}{l}<0.0001 \\
{[<0.0001]}\end{array}$ & & \\
\hline Table 5, Column 3: Cumulative Income2 & $\begin{array}{l}13.7963^{* * *} \\
{[3.3891]}\end{array}$ & & $\begin{array}{l}0.0016^{* * *} \\
{[0.0003]}\end{array}$ & & \\
\hline $\begin{array}{l}\text { Table 6, Column 2: Low Assets x } \\
\text { Cumulative Transfers } \\
\text { Table 6, Column 2: High Assets x } \\
\text { Cumulative Transfers }\end{array}$ & & & & $\begin{array}{l}0.4772 * * * \\
{[0.0089]} \\
-0.0185^{* * *} \\
{[0.0033]}\end{array}$ & $\begin{array}{l}-0.0544 * * * \\
{[0.0058]} \\
0.5020 * * * \\
{[0.0106]}\end{array}$ \\
\hline $\begin{array}{l}\text { Table 6, Column 3: Low Assets x } \\
\text { Cumulative Transfers } \\
\text { Table 6, Column 3: High Assets x } \\
\text { Cumulative Transfers }\end{array}$ & & & & $\begin{array}{l}0.5156^{* * * *} \\
{[0.0107]} \\
-0.0146^{* * *} \\
{[0.0044]}\end{array}$ & $\begin{array}{l}-0.0569 * * * \\
{[0.0083]} \\
0.5540 * * * \\
{[0.0111]}\end{array}$ \\
\hline Table 7, Column 4: Cumulative Transfers & $\begin{array}{l}0.4247 * * * \\
{[0.0122]}\end{array}$ & $\begin{array}{l}0.0077 \\
{[0.0119]}\end{array}$ & & & \\
\hline $\begin{array}{l}\text { Table 7, Column 4: Cumulative Transfers } \\
\text { X Early }\end{array}$ & $\begin{array}{l}-0.1171^{* * *} \\
{[0.0084]}\end{array}$ & $\begin{array}{l}0.5594 * * * \\
{[0.0094]}\end{array}$ & & & \\
\hline Table 7, Column 5: Cumulative Transfers & $\begin{array}{l}0.4828 * * * \\
{[0.0128]}\end{array}$ & $\begin{array}{l}0.0198 \\
{[0.0114]}\end{array}$ & & & \\
\hline $\begin{array}{l}\text { Table 7, Column 5: Cumulative Transfers } \\
\text { X Early }\end{array}$ & $\begin{array}{l}-0.0505^{* * * *} \\
{[0.0086]}\end{array}$ & $\begin{array}{l}0.5887^{* * * *} \\
{[0.089]}\end{array}$ & & & \\
\hline Table 7A, Column 4: Cumulative Income & $\begin{array}{l}0.6328 * * * \\
{[0.0983]}\end{array}$ & $\begin{array}{l}-0.0345 \\
{[0.0755]}\end{array}$ & & & \\
\hline $\begin{array}{l}\text { Table 7A, Column 4: Cumulative Income } \\
\text { X Early }\end{array}$ & $\begin{array}{l}-1.3485^{* * *} \\
{[0.0847]}\end{array}$ & $\begin{array}{l}2.6807^{* * *} \\
{[0.0510]}\end{array}$ & & & \\
\hline Table 7A, Column 5: Cumulative Income & $\begin{array}{l}0.7086 * * * \\
{[0.0929]}\end{array}$ & $\begin{array}{l}-0.0334 \\
{[0.0703]}\end{array}$ & & & \\
\hline $\begin{array}{l}\text { Table 7A, Column 5: Cumulative Income } \\
\text { X Early }\end{array}$ & $\begin{array}{l}-1.1950^{* * *} \\
{[0.0884]}\end{array}$ & $\begin{array}{l}2.8283 * * * \\
{[0.0490]}\end{array}$ & & & \\
\hline
\end{tabular}

Notes: Each row is the first stage for one endogenous variable. See notes to respective tables. Kleibergen-Paap statistics reported with second stage. Robust standard errors clustered by village in brackets. ${ }^{* * *} \mathrm{p}<0.01,{ }^{* *} \mathrm{p}<0.05,{ }^{*} \mathrm{p}<0.10$. 


\section{Appendix D: Additional Assets}

Appendix Table 7 presents results from specifications comparable to those reported in Tables 4-7 in the text for additional energy-using assets. To ease comparison we report only the most relevant statistic from each table. For comparability, we reproduce the results for refrigerators in the first column of the table. Our statistical power and the segment of the households included in the specifications both vary by assets. For example most households have radios at baseline, reducing the estimation sample significantly and focusing the estimation on the poorest households. In contrast, only the very wealthiest households acquire cars. While it is hard to draw strong inferences from only a few heterogeneous assets, the results in Appendix Table 6 are generally supportive of our model. Examining the linear and nonlinear income and wealth effects - Table 4 , and 5 rows, we see the predicted positive linear income effects and positive income squared effects all but two assets. ${ }^{3}$ In the Table 6 row we see non-zero, positive predicted wealth effects for larger assets, where the binary division of baseline wealth is likely relevant. In the Table 7 row we can make direct magnitude comparisons across assets because the units of the compensating income measure are independent of assets. We note that the only asset for which we can reject the refrigerator estimate of about 15,000 pesos is for stoves, for which the effect is even larger. And the only point estimate with a negative sign is for cars and imprecisely measured. ${ }^{4} 5$

\footnotetext{
3 Fan ownership was not collected after 2001, so all the households had received lower treatments. Gas water heaters show little penetration or acquisition, perhaps indicating that even the higher income households are still too poor to acquire them.

4 The income nonlinearities are very strong for cars. This is what we would expect if the investment effects from treatment are particularly large for these households - receiving the transfers earlier allows more investments, yielding greater poorly measured income.

5 For water heaters and cars, repeating these specifications using transfers and through 2007 results in the predicted positive signs. This similar specification is unavailable for fans since they were not included in 2007 either.
} 
APPENDIX TABLE 7-OTHER ASSETS

\begin{tabular}{|c|c|c|c|c|c|c|c|c|c|}
\hline & Refrigerator & $\begin{array}{l}\text { Washing } \\
\text { Machine }\end{array}$ & Stove & TV & Blender & $\begin{array}{l}\text { Radio/ } \\
\text { Stereo }\end{array}$ & Fan & Car & $\begin{array}{l}\text { Water } \\
\text { Heater }\end{array}$ \\
\hline \multicolumn{10}{|l|}{ Table 4: Income Effects } \\
\hline Cumulative Income & $\begin{array}{l}0.016^{* * *} \\
{[0.005]}\end{array}$ & $\begin{array}{l}0.005 \\
{[0.004]}\end{array}$ & $\begin{array}{l}<0.001 \\
{[0.005]}\end{array}$ & $\begin{array}{l}0.024^{* *} \\
{[0.011]}\end{array}$ & $\begin{array}{l}0.031 * * * \\
{[0.009]}\end{array}$ & $\begin{array}{l}0.022 \\
{[0.014]}\end{array}$ & $\begin{array}{l}-0.001 \\
{[0.005]}\end{array}$ & $\begin{array}{l}0.003 \\
{[0.004]}\end{array}$ & $\begin{array}{l}0.001 \\
{[0.002]}\end{array}$ \\
\hline \multicolumn{10}{|l|}{ Table 5: Nonlinear Income Effects } \\
\hline Cumulative Income & $\begin{array}{l}-0.0059 \\
{[0.0108]}\end{array}$ & $\begin{array}{l}-0.0098 \\
{[0.0073]}\end{array}$ & $\begin{array}{l}-0.0029 \\
{[0.0092]}\end{array}$ & $\begin{array}{l}0.0023 \\
{[0.0186]}\end{array}$ & $\begin{array}{l}0.0090 \\
{[0.0172]}\end{array}$ & $\begin{array}{l}0.0134 \\
{[0.0194]}\end{array}$ & $\begin{array}{l}-0.0039 \\
{[0.0066]}\end{array}$ & $\begin{array}{l}-0.0147 * * \\
{[0.0070]}\end{array}$ & $\begin{array}{l}0.0027 \\
{[0.0023]}\end{array}$ \\
\hline Cumulative Income 2 & $\begin{array}{l}0.0009 * * \\
{[0.0004]} \\
\end{array}$ & $\begin{array}{l}0.0006^{* *} \\
{[0.0003]} \\
\end{array}$ & $\begin{array}{l}0.0001 \\
{[0.0003]}\end{array}$ & $\begin{array}{l}0.0009 \\
{[0.0007]}\end{array}$ & $\begin{array}{l}0.0010 \\
{[0.0007]}\end{array}$ & $\begin{array}{l}0.0005 \\
{[0.0006]}\end{array}$ & $\begin{array}{l}0.0002 \\
{[0.0003]}\end{array}$ & $\begin{array}{l}0.0007^{* * *} \\
{[0.0002]}\end{array}$ & $\begin{array}{l}-0.0001 \\
{[0.0001]} \\
\end{array}$ \\
\hline \multicolumn{10}{|l|}{ Table 6: Wealth Effects } \\
\hline $\begin{array}{l}\text { Difference between Cumulative Transfers } \\
\text { X High Assets and Cumulative Transfers } \\
\text { X Low Assets }\end{array}$ & $\begin{array}{l}0.0175^{* * *} \\
{[0.0061]}\end{array}$ & $\begin{array}{l}0.0114 * * * \\
{[0.0040]}\end{array}$ & $\begin{array}{l}0.0036 \\
{[0.0057]}\end{array}$ & $\begin{array}{l}-0.0012 \\
{[0.0112]}\end{array}$ & $\begin{array}{l}0.0119 \\
{[0.0094]}\end{array}$ & $\begin{array}{l}-0.0030 \\
{[0.0171]}\end{array}$ & $\begin{array}{l}-0.0017 \\
{[0.0063]}\end{array}$ & $\begin{array}{l}0.0155^{* * *} \\
{[0.0043]}\end{array}$ & $\begin{array}{l}-0.0008 \\
{[0.0018]}\end{array}$ \\
\hline \multicolumn{10}{|l|}{ Table 7: Timing Effects } \\
\hline $\begin{array}{l}\text { Compensating Income at } 2003 \text { Median } \\
\text { Cumulative Income (Ten Thousand }\end{array}$ & $1.499 * *$ & 1.361 & $3.385 * *$ & 0.519 & $1.368 * * *$ & 0.092 & $1.130^{*}$ & -1.156 & 2.113 \\
\hline Pesos) & {$[0.585]$} & {$[1.057]$} & {$[1.438]$} & {$[0.815]$} & {$[0.474]$} & [1.107] & {$[0.595]$} & [4.179] & {$[2.175]$} \\
\hline
\end{tabular}

Notes: Each cell reflect the coefficient of interest from a different regression except that linear and squared terms from Table 5 specifications are from the same regression. Column (2) from Tables 4, $5 \& 6$, and column (4) from Table 7. All specifications and instruments as described in the respective tables. All rounds through 2003 included except where that Washing machine and Car not reported in 1999 and Fan not reported in 2003. Radio/Stereo reflects a radio and/or stereo as questions varied by round. Refrigerator entry repeats results from tables in text. Robust standard errors clustered by village in brackets. ${ }^{* * *} \mathrm{p}<0.01,{ }^{* *} \mathrm{p}<0.05,{ }^{*} \mathrm{p}<0.10$. Kleibergen-Paap Wald F-stat on excluded variables not reported. All exceed 7. 


\section{Appendix E: Empirical Results on Energy Consumption}

Previous research suggests that the response of energy use to income conditional on assets is small. ${ }^{6}$ However those studies are from the developed world and non-poor. We examine the relationship between income and household energy use in order to evaluate the extent to which growth in electricity consumption is driven by higher income directly or as a consequence of households' asset acquisitions. Specifically, we examine whether higher household income, driven by Oportunidades transfers, leads to increased electricity consumption conditional on appliance holdings. We compare the conditional income effect to estimates of the effect of an appliance acquisition on electricity use. Our data allow us to obtain estimates from low-income households in Mexico.

Using cross-sectional data from the 2007 ENCEL, we estimate:

$$
\text { electricity use } e_{i}=\beta_{1}+\beta_{2} \text { Current transfers } s_{i}+\beta_{3} a_{i}+\beta_{4} X_{i}+\delta_{v}+\epsilon_{i}
$$

where electricity $u_{s} e_{i}$ is household $i$ 's bi-monthly expenditure for electricity and current transfers $i$ is the average Oportunidades bi-monthly cash transfer in 2007 for household $i . a_{i}$ is a measure of assets - either a variable that takes a value of either 0 or 1 to indicate refrigerator ownership by household $i$, or an energy-use-weighted sum of electricity appliances owned by household $i .{ }^{7} X_{i}$ is a vector of household covariates, $\delta_{v}$ captures village-level fixed effects and $\varepsilon_{i}$ is the error term.

Note that we observe only whether or not a household owns a particular type of appliance (e.g., a refrigerator or washing machine) and have no information on its purchase or usage price, nor on any of its other characteristics. We do estimate village-fixed effects, which, along with our instruments discussed below, control for much of the cross-household variation in energy prices, as electricity prices in Mexico are regulated at the regional level. We also observe electricity use only once, in 2007 , so our analysis of energy use is purely cross-sectional.

\footnotetext{
6 See, e.g., Dubin and McFadden, 1984; Hsiao and Mountain, 1985; Reiss and White, 2008.

${ }^{7}$ For each electricity using asset the household owns, we assign a weight, according to estimates by the Comisión Federal de Electricidad (2010) of average electricity consumption for the asset for typical Mexican households. Those weights, in $\mathrm{kWh} / \mathrm{month}$ are: Refrigerator, 120; Light bulbs (1+1 per room), 9; Washing Machine, 13; TV, 10; Radio/Stereo/CD Player, 8; Blender, 2.
} 
As described in the text, transfers vary across households as a nonlinear function of family structure. So long as the variation in the current transfer amounts is not correlated with the propensity to use energy or own an appliance, conditional on household controls, our specification will yield unbiased estimates. On the other hand, unobservable household characteristics may be driving appliance use and acquisition decisions. For example, a negative health shock within a household may increase the utility from a gas stove, and may also make the household more likely to use it.

To address the endogeneity concerns, we instrument for appliance ownership using a crosssectional specification analogous to those described in the text. We instrument for asset ownership with potential cumulative transfers, potential cumulative transfers interacted with early status, and asset ownership in $1997 .{ }^{\circ}$ Our specification is identified by variation in PCT amounts and randomized early status.

It is conceivable, however, that there is additional endogeneity if the age structure and gender of children influences the value of using and/or owning assets. Because our data is only crosssectional, we cannot employ the fixed-effects approach in the acquisition estimation in the text. However, the similarity between the estimates of the asset acquisition models using household controls and those using fixed effects suggest that the included household controls capture the relevant variation in the value of owning an asset. So, we include the same set of household controls as we did in Tables 5-9. In addition, because of the same endogeneity concern described with respect to asset acquisition regarding actual transfers, we instrument for current transfers using potential current transfers.

Appendix Table 8 presents several estimates using a linear model. We report robust standard errors clustered at the village level. Columns (1) and (2) do not control for asset ownership, and estimates suggest a marginal propensity to consume electricity out of transfers of about $1 \%$. However, as this paper emphasizes, these estimates are mis-specified in the sense that electricity consumption is not merely a function of current income, but also of the stock of energy using assets. Moreover, because past income and past asset acquisition is likely correlated with current

\footnotetext{
${ }^{8}$ We do not use the early indicator by itself as an instrument because it is collinear with the village fixed effects. We obtain similar results if we estimate state instead of village fixed effects and include early as an instrument.
} 
income, the coefficients in columns (1) and (2) capture some combination of short- and long-run responses to income. What columns (3)-(6) show is the strong role of assets in mediating energy use. Columns (3) adds a control for asset ownership, and the coefficient suggests that for every additional aggregated 100-kWh per month of energy-using assets a household owns, bi-monthly energy expenditure increases by 43 pesos. ${ }^{9}$ Once we control for assets, the marginal propensity to consume electricity is not significantly different than zero though the size of the coefficient is consistent with short run-income elasticities from the developed world (Hsiao and Mountain, 1985). This is consistent with electricity use being dictated by the extensive margin of asset acquisition, not an intensive margin of income. When we instrument to allow for potential endogeneity, the estimated effects of asset ownership are larger and the marginal propensity to consume is even smaller. ${ }^{10}$ Columns (5) and (6) report the same specifications but replace the asset aggregate with a dummy for refrigerator ownership with similar results. Using the coefficients in Column (5) adding a refrigerator to a household has the equivalent energy expenditure effect of increasing their current bi-monthly transfers by 7,900 pesos. These results are consistent with the hypothesis that the main pathway by which increases in income lead to energy use is through appliance acquisition, not through increased usage of existing appliances. Because of this, understanding energy using asset acquisition, not simply income growth, is important to understanding the likely growth in demand for energy.

\footnotetext{
9 The implied retail cost of electricity suggested by this coefficient is about a third to half of the rates faced by low consuming Mexicans. The coefficient could be biased downwards by measurement error or systematic correlations between households that have energy efficient appliances, which could cause the index to misrepresent the energy mix of the home, and households with high transfers or reporting of monthly instead of bimonthly electricity bills. Also, this may reflect electricity theft or payment at the even lower agricultural rates.

${ }^{10}$ Because these households do not own energy using assets whose electricity usage is easy to meaningfully change, such as air conditioners, it is plausible that these households would have electricity usage which is less responsive to income than those in the developed world.
} 
APPENDIX TABLE 8 - EFFECT OF TRANSFERS ON ELECTRICITY DEMAND CONDITIONAL ON ASSETS

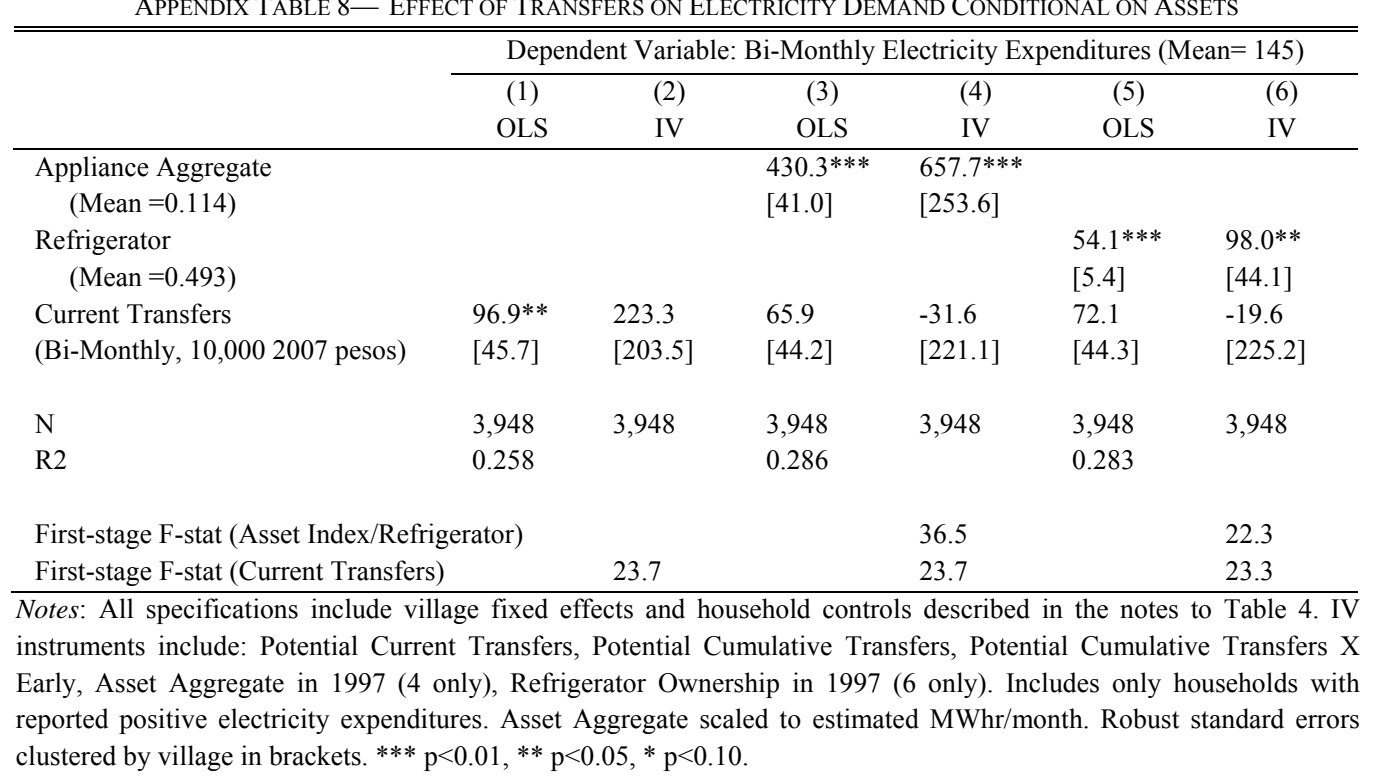




\section{APPENDIX REFERENCES}

Comisión Federal de Electricidad. 2010. "Tabla de Consumo" Available at: http://www.cfe.gob.mx/sustentabilidad/ahorroenergia/Paginas/Tabladeconsumo.aspx

Hsiao, Cheng and Dean Mountain. 1985. "Estimating the Short-Run Income Elasticity of Demand for Electricity." Journal of the American Statistical Association, 80: 259-265.

Reiss, Peter and Matthew White. 2008. "What Changes Energy Consumption? Prices and Public Pressures,” RAND Journal of Economics, 39(3):636-663. 